\title{
Demographics of OCD and Effective Treatment: Brief Report
}

\author{
Rufino $\mathrm{KA}^{1-3}$, Werner $\mathrm{C}^{5 *}$ and Mc Ingvale $\mathrm{E}^{4,5}$ \\ ${ }^{1}$ Department of Psychiatry, Baylor College of Medicine, Houston, TX, USA \\ ${ }^{2}$ University of Houston- Downtown, USA \\ ${ }^{3}$ The Menninger Clinic, Houston, TX, USA \\ ${ }^{4}$ McLean Hospital, Belmont, MA \\ ${ }^{5}$ Houston OCD Program, Houston, TX, USA \\ *Corresponding author: Werner C, Houston OCD Program, Houston, TX, USA
}

\section{ARTICLE INFO}

Received: 幽 October 25, 2019

Published: 幽 November 05, 2019

Citation: Rufino KA, Werner C, Mc Ingvale E. Demographics of OCD and Effective Treatment: Brief Report. Biomed J Sci \& Tech Res 22(3)-2019. BJSTR. MS.ID.003761.

\begin{abstract}
Obsessive-Compulsive Disorder (OCD) is a common and debilitating disorder that worsens without appropriate treatment. Due to stigma, lack of resources, demographics, and cultural bias many individuals are not receiving appropriate care. The aim of this study was to examine treatment disparities based on geographic locations. Results from this study found that Exposure and Response Prevention (ERP) was more likely to be used with individuals living in the United States and Australia than those living in Asia and India. Additionally, individuals living in the United States, South and Central America were more likely to take medication for OCD. Results also revealed that individuals living in the United Kingdom were less likely to try medication. These results highlight the need for education at a global level around effective treatment for OCD.
\end{abstract}

Keywords: OCD; ERP; Medication; Demographic Locations

\section{Introduction}

Obsessive-Compulsive Disorder (OCD) is a severe and disabling mental illness that worsens over time without effective treatment. Evidence based Exposure and Response Prevention (ERP) in combination with medication management of Selective Serotonin Reuptake Inhibitors (SSRIs) is the preferred treatment for OCD [1]. The lifetime prevalence of OCD is approximately 2-3\% of the general population [1] which translates to roughly 200 million people globally. It takes an average of 17 years for an individual to receive appropriate treatment (i.e. ERP and medication management) from the onset of symptoms (Jenike, 2004). The prevalence rates of OCD among ethnic minorities are similar across the board, however there is a clear underrepresentation of mental health services among ethnic minorities [2]. Ethnic minorities are less likely to receive adequate treatment for OCD due to a wide range of factors including low income, racism, stigma surrounding mental health, family factors, and cultural differences $[3,4]$. Acknowledging the specific barriers in treatment amongst ethnicities will provide a focus for what disparities need to be addressed [5]. Asian Americans and Pacific Islanders use mental health services less frequently than any other minority [6].

Additionally, African Americans, Latinos, Asian Americans, and Native Americans are more likely to drop out of treatment prematurely; additionally, African Americans and Latin Americans are less likely to be prescribed medications [5]. When accounting for consistent OCD prevalence rates globally and across all minority groups [7] understanding what factors (i.e. cost, stigma, religious beliefs, racism, demographic locations) are creating treatment resistance may assist in addressing these barriers by providing more knowledge to the public about these treatment inefficiencies. One study evaluating 166 college students found that Caucasians attended a much greater degree of therapy sessions than those of African American, Asian American, and Latino descents. ObsessiveCompulsive Disorder is a common and disabling disorder that is undertreated among all ethnicities [8] and many countries do not 
have adequate treatment readily available for those suffering with OCD or related disorders [9].

When considering ethnic minorities, having a diagnosis of OCD is in proportion to the general population [2] however access to and utilization of treatment varies greatly. Understanding the specific treatment disparities related to OCD globally will allow for enhancements to education and awareness in order to lessen this gap. The purpose of this paper is to evaluate users of a self-help OCD website to better understand minority's access to and utilization of psychological and pharmacological treatment for OCD.

\section{Method}

The present study included 2094 participants ranging from 7 to 77 years of age $(M=30.98, S D=12.06)$. Participant data used for this study was de-identified data from the OCD Challenge website (a free self-help website for OCD) with institutional review board (IRB) approval. Participants voluntarily signed up for this program and consented to data use prior to completing questionnaires used in this study. Demographic questions around medication use, ERP and country of residence were used. The sample was slightly skewed toward female $(62.0 \%)$, and a majority $(74.4 \%)$ was Caucasian followed by Asian/Pacific Islander (6.9\%) and individuals who preferred not to disclose (5.9\%). Most participants report their residence as the United States (US) (75.3\%) followed by the United Kingdom (UK) (6.7\%) and other European countries (4.3\%).

\section{Results}

Results revealed a significant association between country of residence and whether the individual has reported taking medication $\left[\chi^{2}(9)=27.79 ; \mathrm{p}=.001\right]$. Follow up analyses, utilizing a Bonferroni correction, revealed significant individual chi square tests for the participants living the US $\left[\chi^{2}(1)=7.13 ; p=.008\right]$, the UK $\left[\chi^{2}(1)=7.18 ; p=.007\right]$, and South and Central America $\left[\chi^{2}(1)\right.$ $=7.73 ; \mathrm{p}=.005]$. Participants living in the US and South or Central America were more likely to report having taken medication, while participants living in the UK were more likely to report they had not. Results also revealed there was a significant association between country of residence and whether the participant reported experience with ERP $\left[\chi^{2}(9)=29.61 ; p=.001\right]$. Follow up analyses, utilizing a Bonferroni correction, revealed significant individual chi square tests for the participants living in India $\left[\chi^{2}(1)=12.82 ; p<\right.$ $.001]$, Australia $\left[\chi^{2}(1)=5.11 ; p=.024\right]$, and Asia $\left[\chi^{2}(1)=7.40 ; p=\right.$ .007]. More specifically, participants living in Australia were more likely to report participating in ERP, while participants living in India and Asia were more likely to report they had not.

Finally, results revealed there was no association between country of residence and whether someone was currently taking medication $\left[\chi^{2}(9)=12.17 ; \mathrm{p}=.204\right]$ or whether they had never taken medication $\left[\chi^{2}(9)=14.81 ; p=.096\right]$.

\section{Discussion}

Findings from this study further confirm treatment disparities for OCD that exist based on geographic location. Results indicate that individuals who in the United States, Central and South America were more likely to report past medication use for OCD while individuals in the UK were more likely to report they had not taken medication in the past. Despite this finding, results revealed no association among geographic location and current medication use. Results identified that individuals in Australia were more likely to have engaged in ERP and individuals in Asia and India were more likely to report they had not engaged in ERP treatment, revealing a treatment disparity among country of residence. These findings are limited due to both our sample size and nature of our sample. Individuals from this sample voluntarily accessed a selfhelp website for OCD without a screening metric. Further research should appropriately screen/diagnose OCD and replicate these demographics to confirm study findings.

We know that a treatment gap of $58.2 \%$ exists for OCD in the Americas [10], further indicating that other countries with less treatment engagement may have even higher treatment gaps. This study confirms disparities relating to medication management and ERP for OCD. Medication is utilized to a lessened degree outside of the Americas while ERP is underutilized in Asia and India. Although our findings suggest that Australians may be most likely to have received ERP previously, further research should confirm this finding. We know that OCD prevalence rates remain the same across the globe yet both access to treatment and treatment utilization varies significantly. These findings further corroborate the need for global access to evidence based treatment for OCD, which is recognized as the combination of medication and ERP, in order to lessen the gap across the globe between those diagnosed with OCD and those receiving evidence-based care.

\section{References}

1. Foa EB, Liebowitz MR, Kozak MJ, Davies S, Campeas R, et al. (2005) Randomized, placebo-controlled trial of exposure and ritual prevention, clomipramine and their combination in the treatment of obsessivecompulsive disorder. Am J Psychiatry 162(1): 151-61.

2. De la Cruz LF, Llorens M, Jassi A, Krebs G, Vidal-Ribas P, et al. (2015) Ethnic inequalities in the use of secondary and tertiary mental health services among patients with obsessive-compulsive disorder. The British Journal of Psychiatry 207(6): 530-535.

3. Silberholz EA, Brodie N, Spector ND, Pattishall AE (2017) Disparities in access to care in marginalized populations. Current opinion in pediatrics 29(6): 718-727.

4. Williams MT, Taylor RJ, Himle JA, Chatters LM (2017) Demographic and health-related correlates of obsessive-compulsive symptoms among African Americans. Journal of obsessive-compulsive and related disorders 14: 119-126.

5. Snowden LR (2003) Bias in mental health assessment and intervention: Theory and evidence. American Journal of Public Health 93(2): 239-243.

6. Cheung FK, Snowden LR (1990) Community mental health and ethnic minority populations. Community Mental Health Journal 26(3): 277291. 
7. Washington CS, Norton PJ, Temple S (2008) Obsessive-compulsive symptoms and obsessive-compulsive disorder: A multiracial/ethnic analysis of a student population. The Journal of nervous and mental disease 196(6): 456-461.

8. Stein DJ (2002) Obsessive-compulsive disorder. The Lancet Elsevier 360(9330): 397-405.

9. Ng C, Herrman H, Chiu E, Singh B (2009) Community mental health care in the Asia-Pacific region: using current best-practice models to inform future policy. World psychiatry official journal of the World Psychiatric Association (WPA) 8(1): 49-55.

10. (2013) Pan American Health Organization. Mental health in the Americas: Health in the Americas. World Health Organization. Washington, D.C.

11. Kearney LK, Draper M, Barón A (2005) Counseling Utilization by Ethnic Minority College Students. Cultural Diversity and Ethnic Minority Psychology 11(3): 272-285.

ISSN: 2574-1241

DOI: 10.26717/BJSTR.2019.22.003761

Werner C. Biomed J Sci \& Tech Res

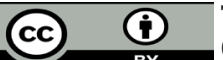

This work is licensed under Creative

Commons Attribution 4.0 License

Submission Link: https://biomedres.us/submit-manuscript.php
12. Kessler RC, Chiu WT, Demler O, Walters EE (2005) Prevalence, Severity, and Comorbidity of 12-Month DSM-IV Disorders in the National Comorbidity Survey Replication. Archives of General Psychiatry 62(6): 617-627.

13. Sue S, Zane N, Young K (1994) Research on psychotherapy with culturally diverse populations. In: Bergin AE, Garfield SL, (Eds.), Handbook of Psychotherapy and Behavior Change, ( $4^{\text {th }}$ edn.). New York, NY: John Wiley Sons Inc; 261-274.

14. Williams MT, Domanico J, Marques L, Leblanc NJ, Turkheimer E (2012) Barriers to treatment among African Americans with obsessivecompulsive disorder. Journal of anxiety disorders 26(4): 555-563.

\begin{tabular}{|ll}
\hline BIOMEDICAL & Assets of Publishing with us \\
\hline RESEARCHES & Global archiving of articles \\
\hline & - Immediate, unrestricted online access \\
\hline
\end{tabular}

